\title{
Clinical Case of Bilateral Rupture of the Patellar Tendon of the Late Diagnosis
}

\author{
Koné Samba ${ }^{1 *}$, Dogba Eric ${ }^{1}$, Nguianbanda Léandre², Kouassi Adélaide ${ }^{3}$, Ledion Anicet ${ }^{1}$, \\ Krah Léopold³, Bana Abdoulaye1, Touré Stanislas', Agoh Serge1 \\ ${ }^{1}$ Service de Traumatologie Orthopédie CHU de Cocody, Abidjan, Côte d'Ivoire \\ ${ }^{2}$ Service de Traumatologie Orthopédie Hôpital des Instructions des Armées (HIA-OBO), Libreville, Gabon \\ ${ }^{3}$ Service de Traumatologie Orthopédie CHU de Bouaké, Bouaké, Côte d'Ivoire \\ Email: ${ }^{\star}$ k.samba06@gmail.com
}

How to cite this paper: Samba, K., Eric, D., Léandre, N., Adélaide, K., Anicet, L., Léopold, K., Abdoulaye, B., Stanislas, T. and Serge, A. (2017) Clinical Case of Bilateral Rupture of the Patellar Tendon of the Late Diagnosis. Open Journal of Orthopedics, 7, 235-240.

https://doi.org/10.4236/ojo.2017.79025

Received: July 24, 2017

Accepted: September 1, 2017

Published: September 4, 2017

Copyright $\odot 2017$ by authors and Scientific Research Publishing Inc. This work is licensed under the Creative Commons Attribution International License (CC BY 4.0).

http://creativecommons.org/licenses/by/4.0/

\begin{abstract}
Defined as a continuity solution on the muscular-osseous-tendinous chain of the knee, ensuring the extension of the leg on the thigh, the traumatic rupture of the knee's extensor apparatus is often reported in literature. They are dominated by patellar fractures. The patellar or quadricipital tendon damage is rare and even exceptional in a bilateral topography. The aim of this work was to highlight the clinical case of bilateral rupture of the patellar tendon of late diagnosis, occurring in an adult with a particular field. It was an adult, who presented a bilateral rupture of the knee extensor apparatus following a minimal traumatism. Anamnesis found a chronic kidney disease correctly follow-up. The diagnosis was delayed so was the surgical management (Krackow's technique and protection by a metallic frame). At 8 months post surgery the functional result is acceptable. The bilateral rupture of the patellar tendon stays a rare pathologic entity, which always seems associated at a particular field. The diagnosis delay (and so did the care) is an important bad prognosis factor. Treatment of this old form (unknown) is exclusively surgical.
\end{abstract}

\section{Keywords}

Knee, Extensor Apparatus, Bilateral, Late

\section{Introduction}

Ruptures of the knee extensor apparatus are uncommon. Most of the time the rupture is expressed under a patellar fracture form or under a quadricipital tendon lesion form [1].

On young patients, violent traumas by direct or indirect shock are the most 
frequent reasons.

Much rarer are the atraumatic forms or following a low energy trauma that occur on pre-existing lesions or particular field and are the prerogative of the elderly.

A rigorous and methodical physical examination is essential in order to make a rapid diagnosis, key to a rapid therapeutic management only guaranteeing an optimal functional result.

The clinical picture is very expressive but, in spite of this, certain ruptures are not diagnosed initially [2]. Bilateral ruptures are difficult to diagnose [3].

Authors report a case of unknown bilateral rupture of the knee tendon on adult on particular field. The objective of this work was to highlight this rare clinical entity and to discuss the therapeutic method and prognosis through a literature review.

\section{Case Report}

This is a 68-year-old man, retired received in consultation for severe knee pain with difficulty during walking. Following a misstep at his home, he fell with reception on knees in flexion. The initial investigations (realised in a non specialised center of the place) have mentioned a knee contusion and an analgesic treatment has been prescribed in front of the persistent symptomatology (deficit on the active leg extension and difficulty during walking), the patient was seen at consultation 2 months later.

The anamnesis highlighted a past medical history of chronic kidney disease under treatment since 5 years.

The clinical examination showed a deficit during active knee extension, a bilateral depression on the anterior part of the knees. Palpation found "anormaly" ascent patellas, without any induced pain or signs of intra-articular collection. There was no evident sign of frontal or sagital laxity. $\mathrm{X}$ ray showed anormal patella ascent with a Caton-Deschamps's [4] index superior to 1.2 on the two knees (Figure 1). Magnetic resonance imaging asked was no realised.

The diagnosis of old patellar's tendon rupture was retained and a surgical indication posed. The intervention was realised in two operating times separated by 04 weeks. The surgical approach was anterior following Krackow's technic (trans-osseous tendon reinsertion inside patella) associated to a metallic strapping in eight number (Figure 2). For the analgesic aim, we placed a posterior
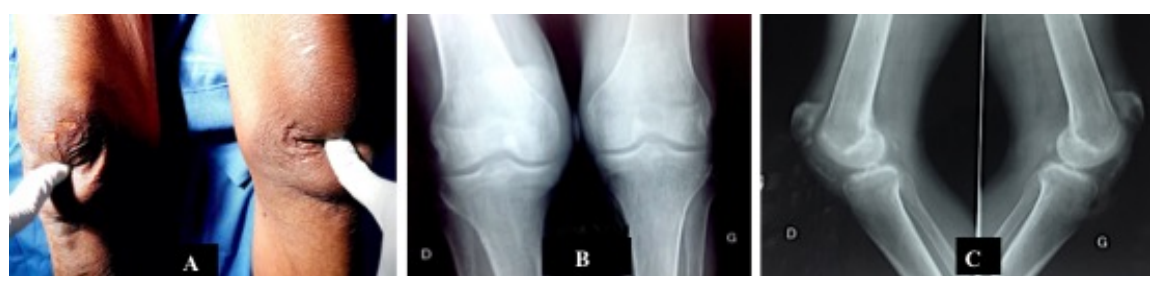

Figure 1. (A) clinical aspect of the knees, bilateral anterior depression; (B) and (C) radiographic aspects of the knees, bilateral patella alta, best viewed on profile. 
splint plaster during a maximum of 15 days. The post-operative $\mathrm{x}$-ray showed a satisfying patella height. A cautious and progressive re-education was instaured and continued a long time. After 8 months, the Parker's score [5] was 7. He doesn't present pain, but a residual flessum, more pronounced to the left $\left(110^{\circ}\right.$ $5^{\circ}-00$ to the right $/ 110^{\circ}-15^{\circ}-00$ to the left) (Figure 3).

\section{Discussion}

The postponement of this unusual clinical case in an elderly subject and attaint of renal insufficiency was aimed at discussing therapeutic modalities and prognoses.

The patellar's tendon rupture is rare and $28 \%$ are unremarked during the initial care. The patella's tendon rupture arrives in the $3^{\text {rd }}$ position of the knee extensor apparatus ruptures, after the transversal patella fracture and the quadricipital tendon rupture [6]. No case of bilateral rupture was observed in our ward in 15 years of common practice. Our clinical case is singular by its bilateral topography and by the initial diagnosis unknown character (fall from his height).

Patellar's tendon bilateral ruptures (traumatic or atraumatic) are very rare, mostly on health subject.

Then some authors 8,9 [6] [7] suggest that when they occur after 40 years
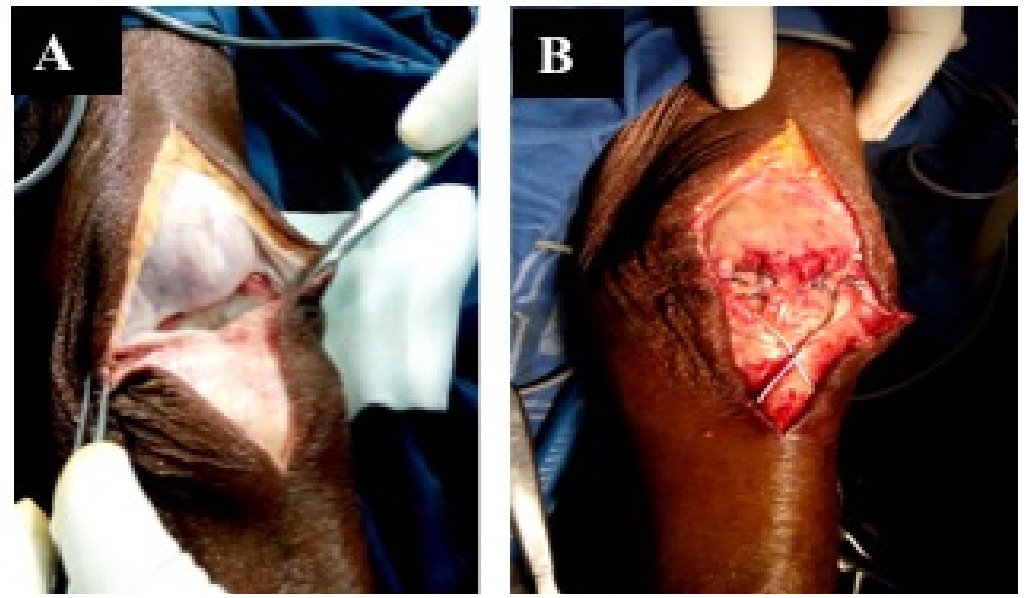

Figure 2. Per-operative. (A) pattelar's tendon desinsertion giving a bald patellar point; (B) bone-tendon suture and enhancement by an 8 strapping.
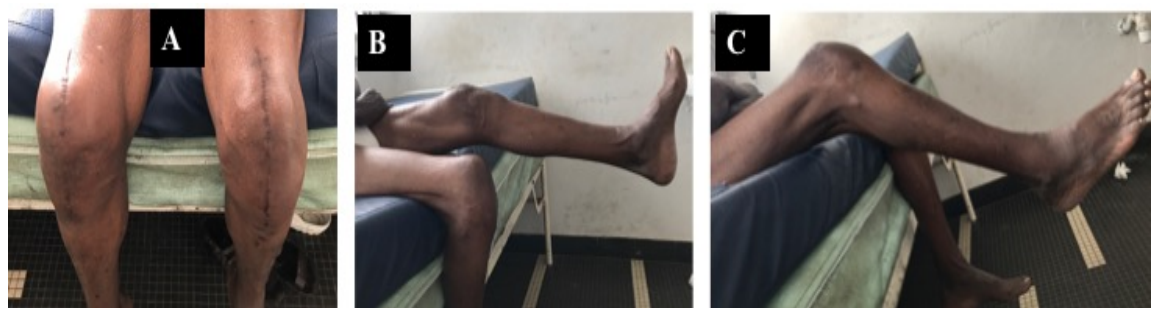

Figure 3. Functional evaluation at 8 months post-operative (A) knees flexion; (B) and (C) left and right residual flessum. 
they must be correlated with an associated pathology or with favoring factors such as autoimmune or systemic diseases; Corticosteroids, tendinopathies and chronic metabolic disorders 8, 9, 10 [6] [7] [8].

The taking of fluoroquinolones or a repeated corticoid infiltration, or anabolisant steroid abuse are also reported as promoting factors [9]. Those pathologies are sources of reshuffle (amyloid deposit, collagen synthesis alteration, tendons vascularisation alteration) linked to a chronic inflammation which weakens tendon.

The interest of this clinical case was that our patient suffered from chronic renal failure, without other factors favoring. Moreover, the initial diagnostic failure is in agreement with the conclusions of Siwek [2] for whom bilateral ruptures are rare and difficult to diagnose.

The evolution of the present case towards an old, unrecognized form was therefore a diagnostic challenge as well both radiological and therapeutic.

At the clinical plan, some elements lead to confusion. Then, sometimes the loss of active knee extension is masked partially by the relative fins integrity, which makes suspected other lesions like knee sprain. This clinical diagnostic error was probably the case of our patient. Only an attentive clinical examination objectives capital signs as: knee tumefaction; a painful under-patellar depression and an abnormally ascending kneecap.

On the standard $\mathrm{x}$-ray, face and profile, the patella is ascent. The axial impact at $30^{\circ}-60^{\circ}$ find the " sunrise" sign with the disparition of the articular space and superposition of the patella on femoral condyles. Caton-Deschamps's radiologic index [4] permit to objective the degree of the patella ascension, which unfortunately as in our clinical case (bilateral lesion) can not be compared to the controlateral side. In doubtful forms, unknown or old, the magnetic resonance imaging stays the gold standard. This last has diagnostic, therapeutic and prognostic interest. It confirms the rupture, appreciate the residual tendinous stump prejudging its biomecanic value [10] [11].

from the diagnostic precocity and the rapidity of the immediate therapeutic care depend the functional prognostic. An early reconstruction (before 6 weeks) give the best results.

In the precocious reparations, all [3] [12] [13] are unanimous on the systematical protection of the reconstruction by a metallic or synthetic lacing whatever the type of reparation(termino-terminal suture or trans-osseous re-insertion according to Krackow).

Beyond 6 weeks, difficulty to restore the patellar's tendon length and then the patella repositioning (centering) increase because of adherences existence, fibrosis on which is associated a retraction of the quadriceps and/or residual tendinous stump. Litterature propose a lot of technics [14] [15] using autograft (semitendinous, gracilis, fascia lata) or allograft (patellar's tendon, Achille's tendon) whose the choice stays a school business. For our patient, we prefered the krackow's technical despite this long diagnostic delay, because of the bilateral 
topography and also fear of aggravating morbidity on this fragile field (chronic kidney disease). Actually, there is no score or reference classification to evaluate results and surgical reparation of patella's tendon lack of large series. At the functional plan our patient is satisfied to have obtained his autonomy (Parker's score was 7) despite the residual flessum. This would be related to the delay in diagnosis. The delay in surgical management is a major prognostic factor [16] [17].

\section{Conclusions}

The bilateral rupture of the patella's tendon remains a rare pathologic entity, which seems always associated to a particular field. The diagnostic delay (and then of the care) is a bad prognostic factor. The management of this old form (unknown) is exclusively surgical with difficulty of repositioning the patella.

The best treatment remains an early diagnostic of those ruptures at the initial stage.

\section{Consent}

The patient and the families were informed that data from the case would be submitted for publication and provided their consent accordingly.

\section{Conflict of Interests}

The authors declare that they have no competing interests.

\section{Author's Contributions}

All the authors contributed of the writing of this manuscript and have read and approved the final version.

\section{References}

[1] Selmi, T., Neyret, P., Rongieras, F. and Caton, J. (1999) Ruptures de l'appareil extenseur du genou et fractures de rotule. EMC SCH Technologies, 44, 730.

[2] Siwek, C.W. and Rao, J.P. (1981) Ruptures of the Extensor Mechanism of the Knee Joint. The Journal of Bone and Joint Surgery. American Volume, 63, 932-937. https://doi.org/10.2106/00004623-198163060-00010

[3] Duthon, V. and Fritschy, D. (2011) Knee Extensor Mechanism Ruptures. Revue Médicale Suisse, 7, 1544-1548.

[4] Caton, J., Deschamps, G., Chambat, P., Lerat, J.L. and Dejour, H. (1982) Patella inféra. Apropos of 128 Cases. Revue de Chirurgie Orthopédique et Réparatrice de 1 Appareil Moteur, 68, 317-325.

[5] Parker, T. (1993) A New Mobility Score for Predicting Mortality after Hip Fracture. The Journal of Bone and Joint Surgery, 75-B, 797-798.

[6] Rose, P.S. and Frassica, F.J. (2001) Atraumatic Bilatéral Patellar Tendon Rupture: A Case Report and Review of the Literature. The Journal of Bone \& Joint Surgery Case Connector, 83, 1382-1386. https://doi.org/10.2106/00004623-200109000-00014

[7] Kellersman, R., Blattert, T.R. and Weckbach, A. (2005) Bilateral Patellar Tendon 
Rupture without Predisposing Systemic Disease or Steroid Use: A Case Report and Review of the Literature. Archives of Orthopaedic and Trauma Surger, 125, 127-133. https://doi.org/10.1007/s00402-004-0782-2

[8] Lu, M., Johar, S., Veenema, K. and Goldblatt, J. (2012) Patellar Tendon Rupture with Underlying Systemic Lupus Erythematosus: A Case Report. The Journal of Emergency Medicine, 43, e35-38. https://doi.org/10.1016/j.jemermed.2009.08.054

[9] Kelly, D.W., Carter, V.S. and Jobe, F.W. (1984) Patellar and Quadriceps Tendon Ruptures: Jumper's Knee. The American Journal of Sports Medicine, 12, 975-980. https://doi.org/10.1177/036354658401200508

[10] Naguib, A.M. and Graham, K.S. (2006) Recurrent Bilateral Rupture of the Patellar Tendons: Tendon Replacement Using Polyester Connective Tissue Prosthesis. Injury Extra, 37, 379-382. https://doi.org/10.1016/j.injury.2006.03.024

[11] Marco, T.L.P.C., Gustavo, H.S.B. and Manuela, B.F.B. (2013) Simultaneous Bilateral Rupture of the Patellar Ligament in Chronic Renal Patient. A Case Report. Revista Brasileira de Ortopedia, 48, No. 5.

[12] Matava, M.J. (1996) Patellar Tendon Ruptures. Journal of the American Academy of Orthopaedic Surgeons, 4, 287-296. https://doi.org/10.5435/00124635-199611000-00001

[13] Greis, P.E., Holmstrom, M.C. and Lahav, A. (2005) Surgical Treatment Options for Patella Tendon Rupture, Part I: Acute. Orthopedics, 28, 672-679.

[14] Nguene-Nyemb, A.G., Huten, D. and Ropars, M. (2011).Chronic Patellar Tendon Rupture Reconstruction with a Semitendinosus Autograft Orthopaedics \& Traumatology. Surgery \& Research, 97, 447-450.

[15] Greis, P.E., Lahav, A. and Holmstrom, M.C. (2005) Surgical Treatment Options for Patella Tendon Rupture, Part II: Chronic. Orthopedics, 28, 765-769.

[16] Rougraff, B.T., Reeck, C.C. and Essenmacher, J. (2010) Complete Quadriceps Tendon Ruptures. Techniques in Knee Surgery, 9, 145-149. https://doi.org/10.1097/BTK.0b013e3181ef5100

[17] Zaidane, A., Haddoun, A.R., Elandaloussi, Y., et al. (2010) Traitement des ruptures négligées du tendon rotulien (à propos de deux cas). Sports Orthopaedics and Traumatology, 27, 189-194. https://doi.org/10.1016/j.jts.2010.10.001

\section{Submit or recommend next manuscript to SCIRP and we will provide best service for you:}

Accepting pre-submission inquiries through Email, Facebook, LinkedIn, Twitter, etc. A wide selection of journals (inclusive of 9 subjects, more than 200 journals)

Providing 24-hour high-quality service

User-friendly online submission system

Fair and swift peer-review system

Efficient typesetting and proofreading procedure

Display of the result of downloads and visits, as well as the number of cited articles

Maximum dissemination of your research work

Submit your manuscript at: http://papersubmission.scirp.org/

Or contact ojo@scirp.org 